\title{
A recurrent mutation of GJB6 in a big Chinese family with Hidrotic ectodermal dysplasia
}

\author{
Yi Zhan ${ }^{* \dagger}$ (D), Shuaihantian Luo ${ }^{\dagger}$, Zixin Pi and Guiying Zhang ${ }^{*}$
}

\begin{abstract}
Hidrotic ectodermal dysplasia (HED) is a rare inherited syndrome characterised by nail dystrophy, palmoplantar hyperkeratosis and alopecia. Four mutations (p.G11R, p.A88V, p.V37E and p.D50N) in gap junction beta 6 (GJB6) gene, which codes connexin30 protein, have been found to cause HED in different populations. Here, we reported a big Chinese family in which 24 patients over five generations were suffered with HED. Sequence analysis identified all 24 patients carry a recurrent missense mutation c.263C > T (p.A88V) in GJB6. Our results reveal gene testing of GJB6 is important for diagnosis, prenatal diagnosis and future gene treatment of HED.
\end{abstract}

Keywords: Hidrotic ectodermal dysplasia, Gene mutations, Sequence analysis, GJB6

\section{Introduction}

Hidrotic ectodermal dysplasia (HED) (OMIM: 129500), also called Clouston syndrome, is a rare autosomal dominant inherited syndrome [1]. In year of 1895, Nicolle and Hallipre first reported this disease [2]. HED occurs worldwide with a very low frequency of 1:100000 [3], while it is high frequent in French-Canadians, which may result from founder effect [4]. The main clinical manifestations of HED are nail dystrophy, alopecia and palmoplantar hyperkeratosis with normal sweat glands and teeth. Besides, eye abnormalities, sensorineural hearing loss, oral leukoplakia may also happen in some sporadic cases $[1,2,5]$. Previous studies have identified that mutations in the gap junction beta 6 (GJB6) gene encoding connexin30 (Cx30) protein was the main cause of HED. Based on gene analysis in different populations, it has been demonstrated that at least four mutation loci (p.G11R, p.A88V, p.V37E and p.D50N) in GJB6 can cause this disorder jointly or

\footnotetext{
*Correspondence: misseven69@csu.edu.cn; lindazgy@csu.edu.cn ${ }^{\dagger}$ Yi Zhan and Shuaihantian Luo contributed equally to this work. Department of Dermatology, The Second Xiangya Hospital of Central South University, Changsha 410011, China
}

independently [6-9]. In this article, we reported a big Chinese family in which 24 patients over five generations were suffered with HED. The proband is a 26year-old young female. Sequence analysis revealed she and other 23 family members all carry a recurrent missense mutation p.A88V (c.263C $>\mathrm{T}$ ) in GJB6. We presented this case to highlight the pathogenic role of p.A88V mutation in GJB6 and emphasize the importance of gene testing in diagnosis, prenatal diagnosis and future gene treatment of HED.

\section{Case history}

The big Chinese HED family is from Hunan Province including 33 patients (16 males and 17 females) over five generations (Fig. 1). The autosomal dominate inheritance can be observed in pedigree. The proband (IV9) is a 26-year-old young woman. Physical examination revealed that her fingernails and toenails are atrophic, short, thickened and brittle with pterygium formation (Fig. 2a, b). The skin all over her body is thickened and hyperkeratosis with dense follicular hyperkeratotic papules (Fig. 2c). Her scalp and body's hair were totally absent since she was born. Only one of the incisors is 


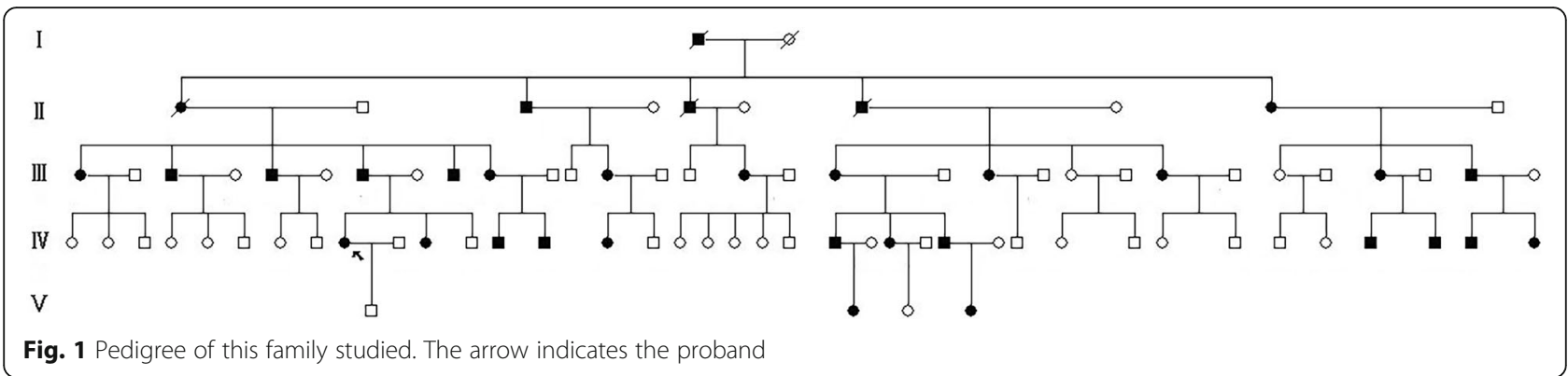

absence partly and other teeth are all normal (Fig. 2d). Sweating and cutaneous sensation are also normal. Skin biopsy of trunk showed hyperkeratosis with normal distribution of eccrine and sebaceous gland, but absence of hair follicles. Almost all the affected individuals have similar clinic features include nail dystrophy, palmoplantar hyperkeratosis and alopecia. Only two patients have hearing disorders (the proband and her father).

Next, we collected blood samples from 24 patients and 6 normal persons for gene testing. Sanger sequencing of DNA from the affected individuals were performed and a heterozygous single nucleotide transition, c. $263 \mathrm{C}>\mathrm{T}$, which results in the amino acid substitution, p.A88V, within GJB6 was identified in all available 24 patients (Fig. 3). None mutations were found in the GJB6 gene in the other 6 healthy individuals.

\section{Discussion}

Connexins are structurally transmembrane proteins that assemble to form gap junctions in human and vertebrate [1]. Gap junctions are essential for many physiological processes, such as normal embryonic development, cellular signal transduction and structural integrity in microvasculature [10]. Mutations in connexins are responsible for a significant burden of heritable human syndromes, including deafness and skin disorders [6]. The human genome contains at least 20 conserved genes that encode distinct but structurally related connexin protein family [10].

Cx30 encoded by GJB6 is an important member in connexin family which is highly expressed in epithelial, especially the palms of the hands and soles of the feet, hair follicles, nail beds and mesenchymal structures of

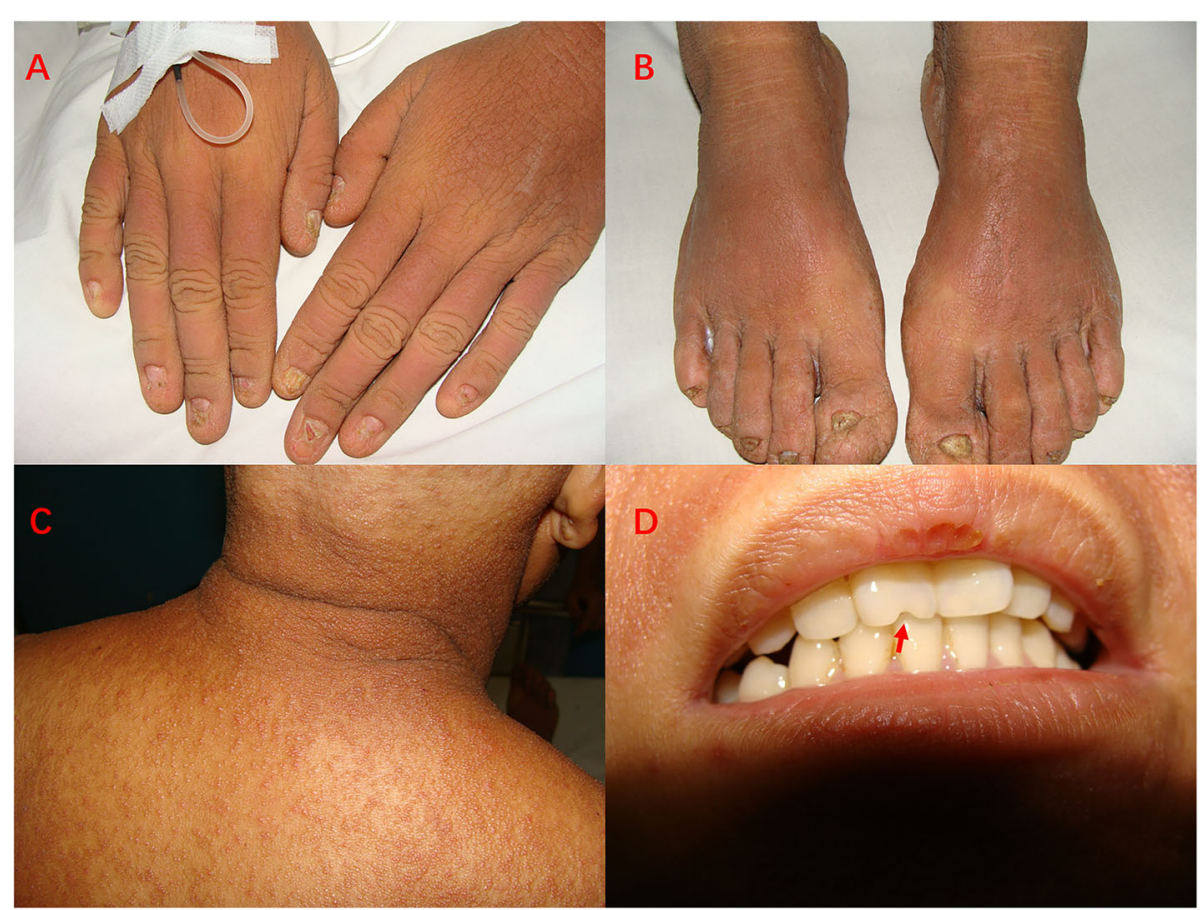

Fig. 2 Clinical features of the proband. a The fingers' nails of the proband are atrophic, thin and brittle. $\mathbf{b}$ The toes' nails are short and thickened. c The skin has dense follicular hyperkeratotic papules. $\mathbf{d}$ One of the incisors is absence partly (red arrow) 


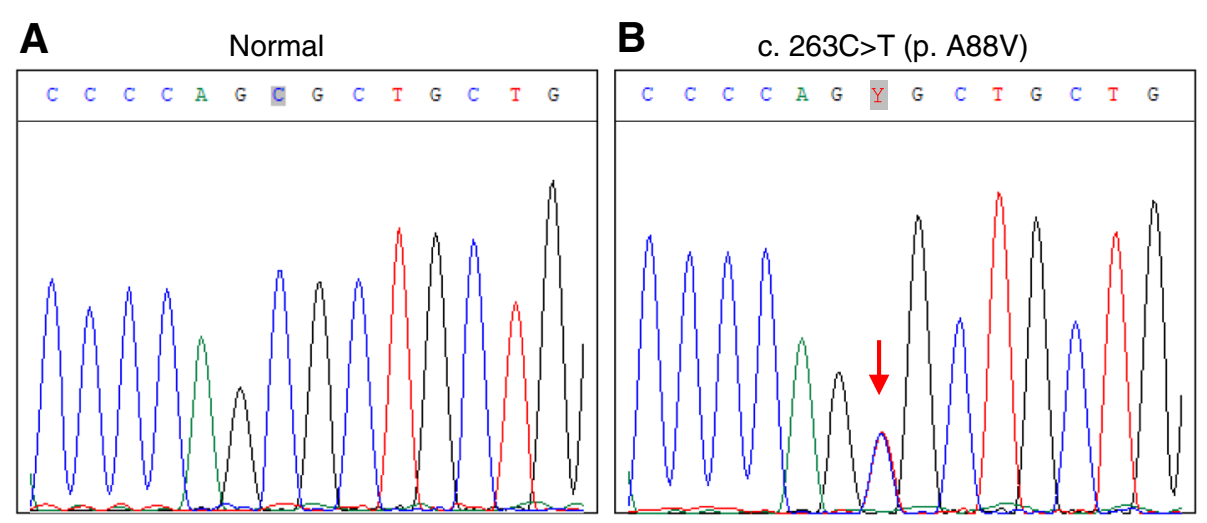

Fig. 3 Molecular genetic analysis of the GJB6 gene with a heterozygous mutation. a Normal GJB6 sequence showing nucleotides 257-270. b The equivalent region from the affected individual with a heterozygous mutation C. 263C > T (arrow)

the inner ear $[2,7,8]$. The intact size and domain of Cx30 are essential to maintain the transport of potassium ions and certain small molecules at gap junctions between cells $[3,5,9]$. In our case, the p.A88V mutation of GJB6 introduced a highly hydrophobic residue in the transmembrane M2 domain of Cx30, which change the polarity of connexin channels and affect intercellular communication.

In year of 2000, Lamartine et al. first identified mutations (p.G11R and p.A88V) in GJB6 could cause HED and these two variants can form intercellular channels and make functional hemichannels which may change paracrine signals [8]. Thus far, different mutation loci can jointly or independently change amino acids sequence in the Cx30 protein which lead to structural modification and abnormalities in the growth, division, and maturation of cells in the hair follicles, nails, and skin. In addition, mice model with same mutation in GJB6 can present with similar hearing dysfunction and hyperproliferative sebaceous glands [11], which also proved the protentional pathogenic role of single nucleotide transition in GJB6.

Different populations may have distinct most frequent variant in GJB6. Notably, p.G11R and p.A88V mutations in GJB6 were recurrently reported in Chinese Han population [3,5]. Whether HED-related mutations in GJB6 have its own spectrum in Chinese Han population needs further observation and investigation $[2,5]$. To the best of our knowledge, p. A88V mutation was only reported in three Chinese families and we reported another family here $[5,12,13]$. In previous reports carrying p. A88V mutation, nail abnormalities in HED usually presented with short, thickened and brittle nail plates mimic pachyonychia congenita $[2,5,12,13]$. However, fingernails of our patient have pterygium formation which may be an unusual manifestation for patients with the same p. A88V mutation described by Sukakul et al. [14].

Because of the rarity of HED, it is difficult to be diagnosed. Gene testing should be the most effective and accurate method in diagnosis of this congenital syndrome especially in prenatal diagnosis. Identification of mutations in GJB6 will help those young individuals from the same family avoiding new patients born. Furthermore, mutations in other connexins, such as Cx26 (encoded by GJB2), can cause some overlapping features of HED including nail dystrophy, hair loss, and palmoplantar keratoderma $[5,15]$. Therefore, whole-exome sequencing is needed in some individuals with HED-like characteristic cutaneous findings, especially when no mutations in GJB6.

Currently, there are no effective treatments for HED, and gene therapy is just a concept. However, in recent studies, fetus carrying the mutation can be identified by prenatal diagnosis, which showed prenatal diagnosis supplies a method to prevent the mutated genes from transmitting to next generation and may provide genetic base for gene treatment [2]. More studies are needed to explore the effective treatments of HED in the future.

In conclusion, this case stresses the pathogenic role of p.A88V mutation in GJB6 and highlights the need for genetic testing in patients with characteristic cutaneous findings.

\section{Abbreviations}

HED: Hidrotic ectodermal dysplasia; GJB6: Gap junction beta 6; GJB2: Gap junction beta 2; Cx30: Connexin 30; Cx26: Connexin 26

\section{Acknowledgements}

Not applicable.

\section{Authors' contributions}

All authors have significantly contributed to the manuscript. Yi Zhan and Shuaihantian Luo contributed equally to this work and are co-first authors. The author(s) read and approved the final manuscript.

\section{Funding}

This work was supported by Natural Science Foundation of China (No.81703133).

Availability of data and materials availably. 


\section{Ethics approval and consent to participate}

The authors certify that they have obtained all appropriate patient consent forms. In the form, the patient(s) has/have given his/her/their consent for his/her/their images and other clinical information to be reported in the journal. The patients understand that their names and initials will not be published and due efforts will be made to conceal their identity, but anonymity cannot be guaranteed.

\section{Consent for publication}

The manuscript has not been submitted for publication elsewhere. All authors agree with its contents.

\section{Competing interests}

None of the authors has any potential financial conflict of interest related to this manuscript.

Received: 23 April 2020 Accepted: 13 August 2020

Published online: 25 August 2020

\section{References}

1. Chen N, Xu C, Han B, et al. G11R mutation in GJB6 gene causes hidrotic ectodermal dysplasia involving only hair and nails in a Chinese family. J Dermatol. 2010;37(6):559-61.

2. Reyes-Reali J, Mendoza-Ramos MI, Garrido-Guerrero E, Mendez-Catala CF, Mendez-Cruz AR, Pozo-Molina G. Hypohidrotic ectodermal dysplasia: clinical and molecular review. Int J Dermatol. 2018:57(8):965-72.

3. Zhang XJ, Chen JJ, Yang S, et al. A mutation in the connexin 30 gene in Chinese Han patients with hidrotic ectodermal dysplasia. J Dermatol Sci. 2003;32(1):11-7.

4. Kibar Z, Dube MP, Powell J, et al. Clouston hidrotic ectodermal dysplasia (HED): genetic homogeneity, presence of a founder effect in the French Canadian population and fine genetic mapping. Eur J Hum Genet. 2000; 8(5):372-80.

5. Shi X, Li D, Chen M, et al. GJB6 mutation A88V for hidrotic ectodermal dysplasia in a Chinese family. Int J Dermatol. 2019:58(12):1462-5.

6. Baris HN, Zlotogorski A, Peretz-Amit G, et al. A novel GJB6 missense mutation in hidrotic ectodermal dysplasia 2 (Clouston syndrome) broadens its genotypic basis. Br J Dermatol. 2008;159(6):1373-6.

7. Essenfelder GM, Bruzzone R, Lamartine J, et al. Connexin30 mutations responsible for hidrotic ectodermal dysplasia cause abnormal hemichannel activity. Hum Mol Genet. 2004;13(16):1703-14.

8. Lamartine J, Munhoz Essenfelder G, Kibar Z, et al. Mutations in GJB6 cause hidrotic ectodermal dysplasia. Nat Genet. 2000;26(2):142-4.

9. Smith FJ, Morley SM, McLean WH. A novel connexin 30 mutation in Clouston syndrome. J Invest Dermatol. 2002;118(3):530-2.

10. Graham SV, Jiang JX, Mesnil M. Connexins and Pannexins: Important Players in Tumorigenesis, Metastasis and Potential Therapeutics. Int J Mol Sci. 2018; 19(6):1645.

11. Bosen F, Schutz M, Beinhauer A, Strenzke N, Franz T, Willecke K. The Clouston syndrome mutation connexin30 A88V leads to hyperproliferation of sebaceous glands and hearing impairments in mice. FEBS Lett. 2014; 588(9):1795-801.

12. Li W, Gao BD, Li LY, Xiao HM, Lu GX. Mutation screening and prenatal diagnosis of hidrotic ectodermal dysplasia in a Chinese family. Zhonghua Yi Xue Yi Chuan Xue Za Zhi. 2006:23(6):618-21.

13. Yang $R$, Hu Z, Kong Q, et al. A known mutation in GJB6 in a large Chinese family with hidrotic ectodermal dysplasia. J Eur Acad Dermatol Venereol. 2016;30(8):1362-5.

14. Sukakul T, Yang HS, Onoufriadis A, Hsu CK. McGrath JA. Pterygium and thinning of nails as an unusual manifestation in Clouston syndrome. J Dermatol. 2019:46(9):e329-30.

15. Liu YT, Guo K, Li J, Liu Y, Zeng WH, Geng SM. Novel mutations in GJB6 and GJB2 in Clouston syndrome. Clin Exp Dermatol. 2015:40(7):770-3.

\section{Publisher's Note}

Springer Nature remains neutral with regard to jurisdictional claims in published maps and institutional affiliations.

Ready to submit your research? Choose BMC and benefit from:

- fast, convenient online submission

- thorough peer review by experienced researchers in your field

- rapid publication on acceptance

- support for research data, including large and complex data types

- gold Open Access which fosters wider collaboration and increased citations

- maximum visibility for your research: over $100 \mathrm{M}$ website views per year

At BMC, research is always in progress.

Learn more biomedcentral.com/submissions 